\title{
O EFEITO DA PRESCRIÇÃO DE CADEIRA DE RODAS DE BASQUETEBOL SOBRE O DESEMPENHO ESPORTIVO'
}

\author{
GRAD. GIANE FRANCINE GARCIA DE MORAES
}

Bacharel em Educação Física pelaUniversidade Estadual de Londrina (Londrina - Paraná - Brasil)

E-mail: gianefgm@gmail.com

\section{GRAD. CRISTIANE REGINA COELHO CANDIDO}

Mestranda em Educação Física pela Universidade Estadual de Londrina (Londrina - Paraná - Brasil)

E-mail: criscoelhouel@hotmail.com

\section{GRAD. BRUNO SECCO FAQUIN}

Mestrando em Educação Física pela Universidade Estadual de Londrina (Londrina - Paraná - Brasil)

E-mail: brunopoti@hotmail.com

\section{ESP. TIAGO GORGATTI}

Especialista em Fisiologia e Biomecânica Aplicada à Locomoção, Reabilitação e Treinamento pela

Faculdade de Medicina da Universidade de São Paulo (São Paulo - São Paulo - Brasil)

E-mail: tgorgatti@gmail.com

\section{Dra. INARA MARQUES}

Doutora em Biodinâmica do Movimento Humano pela Universidade de São Paulo e Professora Adjunto da Universidade Estadual de Londrina (Londrina - Paraná - Brasil)

E-mail: inaramarques@hotmail.com

\section{DR. VICTOR HUGO ALVES OKAZAKI}

Doutor em Biodinâmica do Movimento Humano pela Universidade de São Paulo e

Professor Adjunto da Universidade Estadual de Londrina,

Programa de Educação Tutorial da Educação Física (PET-EF) (Londrina - Paraná - Brasil)

E-mail: vhaokazaki@gmail.com

\section{RESUMO}

Foi analisado o desempenho esportivo de jogadores de basquetebol com utilização de cadeiras de rodas prescritas (específicas) e não-prescritas (genéricas) de acordo com as características de cada atleta. Seis participantes desempenharam testes de velocidade $(20 \mathrm{~m}$ com e

I. Os autores agradecem à CAPES pelas bolsas de mestrado concedidas ao segundo (edital de bolsa PPGEF $n^{\circ} 04 / 201$ I) e terceiro (edital de bolsa PPGEF n04/20 I I) autores e ao MEC/SESU pela bolsa de tutor do PET-EF (edital n 09/20 I0) ao último autor. 
sem bola) e de agilidade (sem bola). Escalas de percepção de esforço e de conforto foram utilizadas após a realização dos testes. Foram verificados melhores desempenho e conforto nos testes realizados com a utilização das cadeiras prescritas. Foi sugerido o uso de cadeiras prescritas especificamente para cada atleta, a fim de otimizar o desempenho e o conforto para a prática do basquetebol em cadeira de rodas.

PALAVRAS-CHAVE: Prescrição de cadeira de rodas; basquetebol em cadeira de rodas; desempenho esportivo; ergonomia.

\section{INTRODUÇÃO}

A utilização da atividade física por pessoas com deficiência física não é algo novo. Na Grécia antiga por volta de 2500 a 3000 a.C. pessoas com deficiência já realizavam a prática de exercícios como finalidade terapêutica (WINNICK, 2004; GORGATTI; GORGATTI, 2008). Após a Primeira Guerra Mundial, exercícios físicos também eram realizados como forma de reabilitação para diminuir as sequelas e amenizar as limitações deixadas pela guerra (CALEFFI, 2008). Porém, apenas após a Segunda Guerra Mundial, é que os governos começaram a se preocupar com os soldados que voltaram da guerra, dando-lhes oportunidades não apenas de reabilitação para realizarem suas atividades independentes, mas também para a prática esportiva com fins competitivos (ADAMS et al., 1985; FREITAS; CIDADE, 2002; GORGATTI; GORGATTI, 2008).

Os programas esportivos com cadeiras de rodas surgiram nos centros de reabilitação em vários Estados Norte Americanos e no Reino Unido, sendo o basquetebol o primeiro esporte em cadeiras de rodas organizado que se tem conhecimento (ADAMS et al., 1985). A prática desta modalidade permitiu demonstrar que uma pessoa com deficiência física também poderia realizar atividades como uma pessoa sem deficiência (ADAMS et al., I 985; GORGATTI; GORGATTI, 2008). Em 1946 foi organizado o 'I Campeonato Nacional de Basquetebol em Cadeiras de Rodas', contando com a participação de I 5 equipes, obtendo grande sucesso e uma grande repercussão para o esporte adaptado (GORGATTI; GORGATTI, 2008). Esta grande repercussão resultou na constituição de federações nacionais e, posteriormente, a federação internacional da modalidade de basquetebol em cadeiras de rodas.

A Federação Internacional de Basquete em Cadeira de Rodas (International Wheelchair Basketball Federation - IWBF), estabelecida em 1993 como o órgão internacional responsável pelo basquete em cadeiras de rodas, auxiliou na regulamentação da competição do basquete em cadeira de rodas (INTERNATIONAL WHEELCHAIR BASKETBALL FEDERATION, 20 I0). Foram estabelecidas normas sobre as regras adaptadas do jogo e as limitações das confecções da cadeira de rodas. 
Por exemplo, o assento na sua região anterior e posterior não pode ultrapassar a altura de $63 \mathrm{~cm}$ do chão. Por sua vez, também, o anti-tip (rodas pequenas traseiras) não podem ultrapassar a extremidade limite oferecida pelas rodas de propulsão, porque estas rodas de propulsão possuem diferenças de tamanho, sendo elas aro 24, aro 25 e aro 26 polegadas que oferecem ao anti-tip uma posição diferenciada podendo ter altura máxima de até dois centímetros do chão (INTERNATIONAL WHEELCHAIR BASKETBALL FEDERATION, 20 I0). Parece que tais características influenciam, diretamente, no desempenho dos participantes. Por conseguinte, a cadeira de rodas é um implemento considerado como parte do atleta e que segue uma série de especificações técnicas que a torna única para cada usuário. No basquete em cadeiras de rodas, a interação cadeira-atleta é preponderante para o desenvolvimento esportivo. Desta forma, a prescrição de medidas corretas para a construção de uma cadeira especificamente adequada ao atleta torna-se elemento fundamental.

A realização da prescrição das medidas para construção de uma cadeira de rodas esportiva, para um atleta com alguma limitação física nos membros inferiores e no tronco, demanda grande conhecimento específico da modalidade esportiva e do atleta. No basquete em cadeiras de rodas, o desenvolvimento individual de cada atleta influencia, diretamente, na prescrição de sua cadeira de roda esportiva. Conforme sua evolução na modalidade esportiva, o atleta desenvolve, além das habilidades específicas, outras capacidades essenciais, tais como: força, agilidade, flexibilidade, etc., que fazem com que sua cadeira necessite cada vez mais de uma personalização para que atenda suas necessidades individuais no jogo.

Dentro deste escopo, é necessário que o indivíduo realize a prescrição da cadeira de rodas sob medida para atletas de basquetebol, pois a cadeira influencia o desempenho do atleta em quadra. Ademais, a prescrição necessita de conhecimento específico para atender às exigências impostas pela IWBF. Apesar da reconhecida necessidade em se utilizar cadeiras de rodas específicas, respeitando as particularidades de cada atleta, ainda não tem sido foco de estudo os efeitos da utilização de diferentes cadeiras de rodas sobre o desempenho de jogadores de basquetebol e também não tem sido investigadas quais as partes da cadeira que podem causar mais desconforto aos participantes durante a sua prática.

Em função do acima exposto, o presente estudo analisou o efeito da utilização de cadeiras de rodas específicas e genéricas sobre o desempenho esportivo em jogadores de basquetebol. Foi levantada a hipótese de que as cadeiras prescritas proporcionarão melhor desempenho e conforto em comparação à cadeira genérica (não-prescrita). Devido à limitação e à escassez de estudos na área de prescrição de cadeira de rodas, o presente estudo tem potencial para ampliar o conhecimento dentro desta área em particular. Além disso, o presente estudo também fornecerá 
subsídios para o entendimento dos fatores relacionados à cadeira que podem afetar o desempenho esportivo de atletas de basquetebol em cadeira de rodas.

\section{MÉTODOS}

\section{AMOSTRA}

A amostra foi composta por 6 praticantes de basquete em cadeiras de rodas, com deficiência física e idade entre 16 a 43 anos $(M=28,33$ anos e $D P=10,1$ ), sendo quatro homens duas mulheres, e que fazem parte da equipe de basquete da Associação Esporte Atitude da cidade de Londrina. Para compor a amostra os participantes deveriam praticar atividades sistematizadas de basquetebol em cadeira de rodas com mais de I ano de experiência e práticas de pelo menos duas vezes por semana. Maiores detalhes sobre as características da amostra foram apresentadas na Tabela I.

Tabela I - Características da amostra

\begin{tabular}{|c|c|c|c|c|c|c|}
\hline & $\begin{array}{l}\text { Idade } \\
\text { (anos) }\end{array}$ & $\begin{array}{l}\text { Peso } \\
(\mathrm{kg})\end{array}$ & Altura (m) & $\begin{array}{l}\text { Experiência com } \\
\text { Basquetebol (anos) }\end{array}$ & $\begin{array}{l}\text { Deficiência } \\
\text { física }\end{array}$ & Motivo da lesão \\
\hline Sujeito I & 25 & 60 & 1,62 & 2 & $\begin{array}{l}\text { LM (TI2 } \\
\text { incompleta) }\end{array}$ & Arma de fogo \\
\hline Sujeito 2 & 20 & 106 & 1,90 & I & LM (T4) & Arma de fogo \\
\hline Sujeito 3* & 16 & 64 & I,70 & 2 & LM $(T \mid I)$ & Acidente de carro \\
\hline Sujeito 4* & 43 & 73 & 1,59 & I & $\begin{array}{l}\text { Seqüela de } \\
\text { Poliomielite }\end{array}$ & -------- \\
\hline Sujeito 5 & 30 & 58 & 1,68 & 4 & LM (TI2) & Acidente de carro \\
\hline Sujeito 6 & 36 & 79 & 1,82 & 3,5 & LM (T4) & $\begin{array}{l}\text { Acidente de } \\
\text { mergulho }\end{array}$ \\
\hline
\end{tabular}

Legenda: LM = Lesão medular; *Participantes mulheres.

\section{INSTRUMENTOS}

Para a caracterização da amostra foi utilizada uma anamnese com perguntas gerais sobre os participantes antes dos testes. Para a realização dos testes, foram utilizados cones (50 cm de altura), fita métrica, fita crepe e fotocélula (MultSprint Full, v.4.0, marca Hidrofit, com Software MultSprint Fotocélulas). Para a realização das tarefas foram utilizados dois tipos de cadeiras de rodas, uma prescrita especificamente 
para cada usuário (cadeira específica) e outra com medida não específica (cadeira genérica). Assim, foram utilizadas 6 cadeiras de rodas específicas e uma cadeira de rodas utilizada como genérica. A cadeira específica foi prescrita por um profissional formado em educação física com mais de 10 anos de experiência trabalhando com equipes de basquetebol em cadeira de rodas. Apenas uma cadeira de rodas genérica, sem medidas específicas apropriadas para os sujeitos, foi utilizada para todos os sujeitos no estudo.

A prescrição das cadeiras de rodas foi realizada de acordo com as dimensões dos membros inferiores e da altura posterior de quadril, levando-se em conta o equilíbrio e volume/possibilidade de movimentação sobre a cadeira de cada sujeito. Os participantes já utilizavam durante suas sessões de treinamento de basquetebol as cadeiras de rodas especificamente prescritas por um período de pelo menos 6 meses. A tabela 2 apresenta a descrição das medidas das cadeiras de rodas utilizadas por cada um dos sujeitos (cadeira $n^{\circ} \mid$ até 6 , respectivamente para os sujeitos I até 6 descritos na tabela I) e a cadeira genérica utilizada (cadeira n`7 na Tabela 2).

Tabela 2 - Medidas das cadeiras específicas e genérica utilizadas no estudo

\begin{tabular}{|c|c|c|c|c|c|c|c|}
\hline \multirow[b]{3}{*}{ Características da Cadeira } & \multicolumn{7}{|c|}{ Cadeira de Rodas } \\
\hline & \multicolumn{6}{|c|}{ Específica } & \multirow{2}{*}{$\frac{\text { Genérica }}{n^{\circ} 7}$} \\
\hline & $n^{\circ} \mid$ & $n^{\circ} 2$ & $n^{\circ} 3$ & $n^{\circ} 4$ & $n^{\circ} 5$ & $n^{0} 6$ & \\
\hline Profundidade do assento (cm) & 42 & 57 & 47 & 44 & 44 & 46 & 42 \\
\hline Altura do assento ao chão dianteira $(\mathrm{cm})$ & 53 & 53 & 50 & 53 & 53 & 53 & 50 \\
\hline Altura do anti tip ao chão (cm) & । & I & I & । & । & I & I \\
\hline Altura do assento ao chão traseira $(\mathrm{cm})$ & 40 & 40 & 40 & 42 & 40 & 40 & 50 \\
\hline Altura do encosto (cm) & 25 & 35 & 28 & 25 & 30 & 40 & 25 \\
\hline Altura do protetor lateral (cm) & 20 & 25 & 20 & 20 & 20 & 20 & 20 \\
\hline Angulação do canote - encosto (graus) & $90^{\circ}$ & $90^{\circ}$ & $90^{\circ}$ & $90^{\circ}$ & $90^{\circ}$ & $90^{\circ}$ & $90^{\circ}$ \\
\hline Largura do assento (cm) & 38 & 45 & 41 & 38 & 34 & 37 & 40 \\
\hline Altura do pedal (cm) & 40 & 46 & 39 & 42 & 40 & 46 & 42 \\
\hline Largura do pedal (cm) & 25 & 30 & 25 & 28 & 25 & 28 & 25 \\
\hline Profundidade do pedal (cm) & 25 & 25 & 25 & 25 & 25 & 25 & 25 \\
\hline Assento rígido (cm) & não & não & não & não & não & não & $\operatorname{sim}$ \\
\hline Roda (polegadas) & 24 & 24 & 24 & 24 & 24 & 24 & 24 \\
\hline Cambagem (graus) & 15 & 15 & 15 & 15 & 15 & 15 & 15 \\
\hline
\end{tabular}




\section{PROCEDIMENTOS EXPERIMENTAIS}

Os procedimentos experimentais da pesquisa foram submetidos e aprovados pelo Comitê de Ética em Pesquisa da universidade local (Parecer $n^{\circ} 211 / 10$, Folha de Rosto n 368578, CAEE n 0 195.0.268.000- I0). Inicialmente, os participantes assinaram um termo de consentimento livre e esclarecido de participação, após, os testes motores foram explicados verbalmente. Foram realizados os testes:

a) velocidade de 20 metros com bola;

b) velocidade de 20 metros sem bola;

c) agilidade em ziguezague sem bola. A ordem dos testes foi pseudo-aleatorizada entre os participantes. Os testes foram realizados em dias diferentes para evitar fadiga.

No teste de velocidade de 20 metros (com e sem a utilização do drible com a bola), o participante, inicialmente parado, deveria percorrer uma distância de 20 metros em linha reta no menor tempo possível. O percurso foi demarcado com cones e fitas adesivas fixadas ao solo para a demarcação do início e da chegada (Figura I). Foi colocado um cone a uma distância de 21 metros como referência para que os participantes não desacelerassem antes do término dos 20 metros do percurso do teste. A fotocélula foi posicionada ao lado dos cones que demarcaram a linha de início e a do final do teste de 20 metros. Na versão do teste de 20 metros com a utilização do drible, o participante iniciou o teste com a bola em seu colo. Foi solicitado aos participantes que iniciassem o percurso com a bola no colo e chegassem com a bola no colo (para evitar possível interferência da bola desativando o sensor da fotocélula antes que o participante ultrapassasse o sensor). Foi permitida a escolha do tipo de drible utilizado pelos participantes, mas a mesma técnica de drible escoIhida deveria ser utilizada com os dois tipos de cadeiras utilizadas. Os participantes apenas foram instruídos para não colocarem a bola no colo ou segurá-la durante o percurso. No teste de agilidade em ziguezague, o participante teve que percorrer uma trajetória situada em um retângulo $(6 \mathrm{~m} \times 9 \mathrm{~m})$, realizando um movimento de ziguezague, sempre realizando a volta ao lado de um cone colocado na posição central do percurso (GORLA, CAMPANA, OLIVEIRA, 2009). Os participantes foram instruídos a realizarem o percurso no menor tempo possível. A Figura I apresenta uma ilustração esquemática do local utilizado com as referências para a realização do teste de velocidade e de agilidade. 


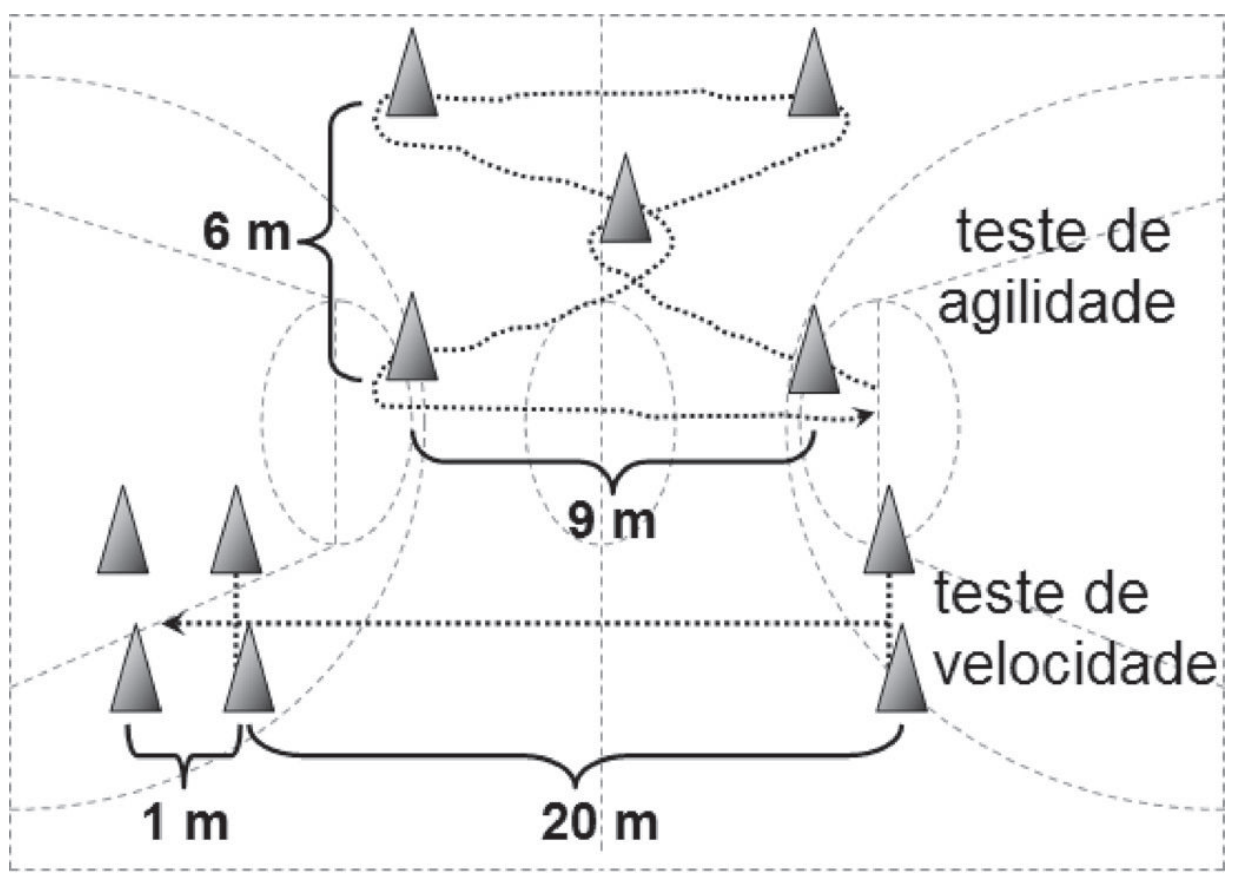

Figura I: Representação esquemática do local de realização do teste de velocidade de 20 metros (realizado com e sem a utilização de drible) e do teste de agilidade em ziguezague (realizado sem bola).

Nos três testes realizados, os participantes tiveram a possibilidade de realizar duas tentativas para conhecimento do percurso, uma mais lenta e outra com maior velocidade, como forma de familiarização. Posteriormente, o percurso foi realizado três vezes com cada cadeira específica ou genérica, buscando-se o menor tempo possível nos testes. Foi realizado um período de cinco minutos de descanso entre as tentativas. Quando ocorreu algum erro durante a realização de algum teste (devido à perda da bola no drible, falha no acionamento do sensor da fotocélula, etc.) o procedimento foi repetido. $\bigcirc$ tempo de desempenho nos testes foi determinado pelo sistema de fotocélula. A média do tempo das três tentativas realizadas com cada cadeira foi utilizada para a análise estatística.

Imediatamente após o término de cada tentativa de teste, com cada tipo de cadeira, foram aplicadas as escalas subjetivas esforço e de conforto. A escala subjetiva de percepção de esforço utilizada foi a escala de Borg adaptada (BORG, 2000), que permitiu ao participante classificar subjetivamente suas percepções de cansaço e níveis de fadiga. Antes da aplicação desta escala, foi fornecida aos participantes uma explicação verbal sobre a forma de indicar seu nível de esforço após a realização das tentativas de teste.

Uma escala de conforto generalizada e uma escala especificando alguns aspectos da cadeira (assento, encosto, apoio dos pés e aro de propulsão) também foram utilizadas, após as tentativas de teste, para avaliar os aspectos de conforto da cadeira. Nesta escala de conforto foi solicitado aos participantes indicarem qual o conforto que eles possuíram para os seguintes itens: 
a) conforto geral proporcionado pela cadeira;

b) conforto proporcionado pela cadeira durante o desempenho do teste;

c) conforto do assento;

d) conforto do encosto;

e) conforto para o apoio dos pés;

f) conforto para a utilização do aro para a propulsão.

Os participantes deveriam indicar um valor de 0 (zero) até 10 (dez), para cada item, no qual 10 seria atribuído para o maior conforto e 0 (zero) para a situação de maior desconforto.

\section{VARIÁVEIS DE ESTUDO}

A variável independente do estudo foi o tipo de cadeira, ou seja, a cadeira prescrita (específica) e a cadeira não-prescrita (genérica). As variáveis dependentes analisadas foram o tempo de desempenho dos testes e as medidas na escala de conforto. A escala de percepção subjetiva de esforço foi utilizada como variável de controle da fadiga entre as condições de teste.

\section{ANÁLISE ESTATÍSTICA}

Os dados foram analisados a partir de estatística descritiva de média e de desvio-padrão. Para estatística comparativa, nas variáveis de tempo de movimento no desempenho dos testes, foi utilizado o teste "t" de Student, para medidas dependentes, após a verificação da normalidade dos dados. Os escores de percepção subjetiva de esforço (Escala de Borg) e de conforto (Escala de conforto) foram analisados por meio do teste de Wilcoxon para amostras pareadas (medidas repetidas). As análises estatísticas foram realizadas através do software Statistica (versão 6.0). O nível de significância adotado foi de $P \leq 0,05$.

\section{RESULTADOS}

A cadeira específica demonstrou melhor desempenho (menor tempo de prova) nos três testes realizados: teste de velocidade sem bola ( $t=-2,54 ; P=0,05)$, teste de velocidade com bola $(t=3,14 ; P=0,02)$ e no teste de agilidade $(t=-2,77$; $P=0,04)$. A Figura 2 ilustra os resultados em média e desvio padrão nos testes realizados com a cadeira específica e genérica. 


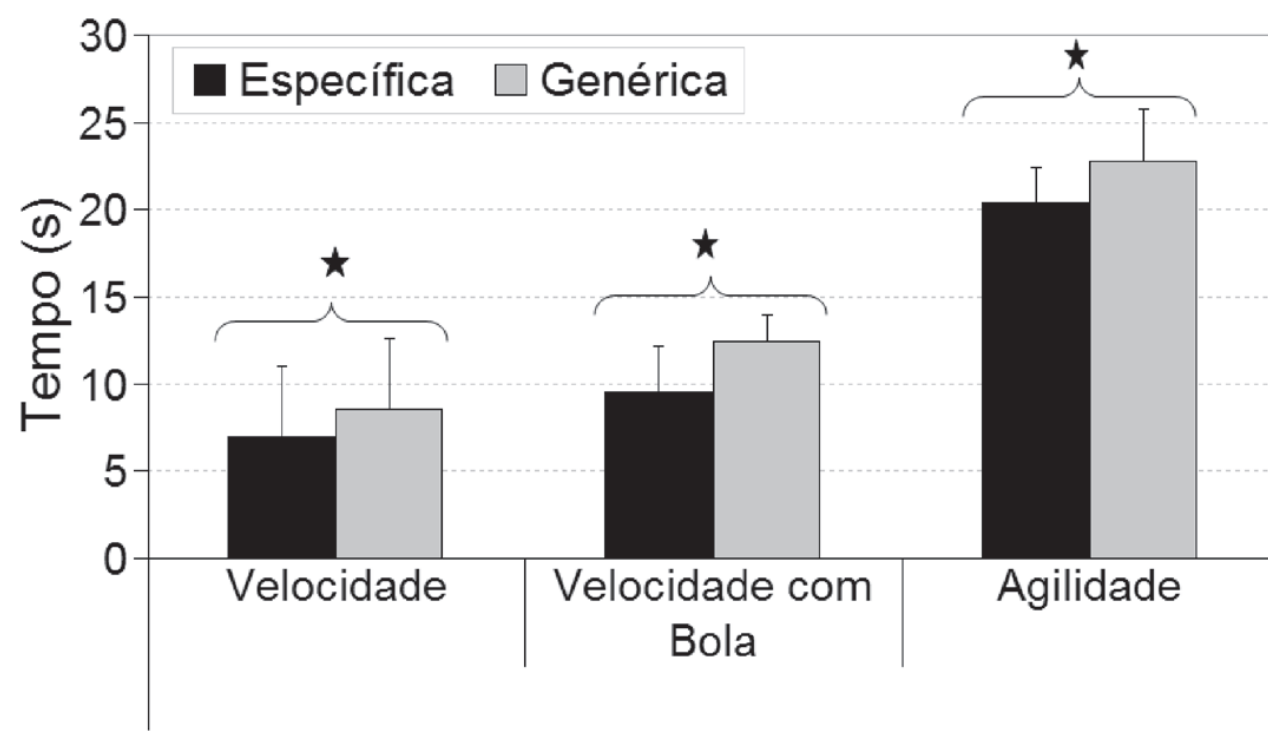

Figura 2: Tempo de movimento (média e desvio padrão) nos testes realizados com a cadeira específica e genérica.

Nota: *diferença significante $(P \leq 0,05)$ entre a cadeira específica e genérica.

Em relação à percepção de esforço (Escala de Borg), não foi verificada diferença entre as cadeiras específica e genérica para o teste de velocidade $(Z=0,01 ; P=1,00)$, teste de velocidade com bola $(Z=1,22 ; P=0,22)$ e teste de agilidade $(Z=0,89$; $P=0,37)$. Tais resultados indicaram que em ambas as cadeiras, os testes foram realizados sem a presença de fadiga e os sujeitos mantiveram a mesma intensidade nos desempenhos dos testes. Outro aspecto que indica a ausência de fadiga, além dos testes terem sido rápidos e com um bom intervalo entre as tentativas, foi o fato dos participantes não indicarem valores de 9 e 10 na escala de Borg (Figura 3).

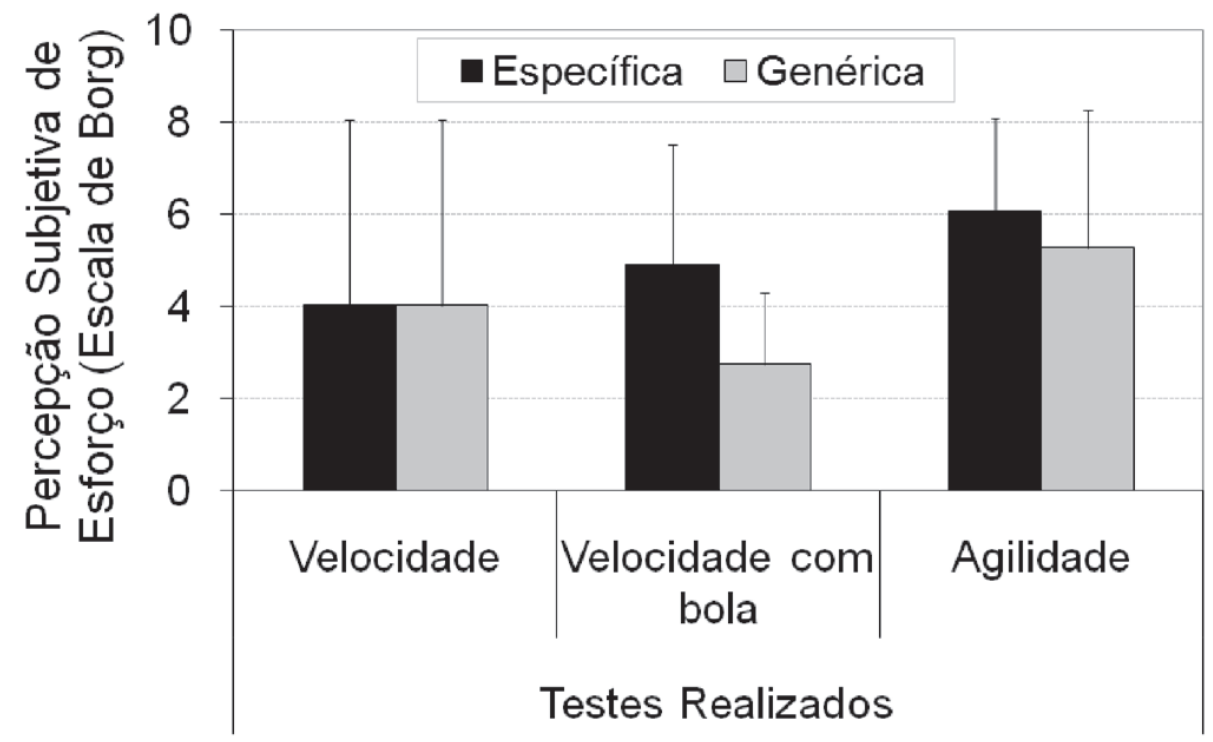

Figura 3: Escala de percepção subjetiva de esforço (média e desvio padrão) nos testes motores realizados com a cadeira específica e genérica. 
Para a escala de conforto durante o teste de velocidade os participantes indicaram melhor conforto utilizando a cadeira específica, tanto de uma forma geral $(Z=2,04 ; P=0,04)$ quanto durante a realização do teste $(Z=2,04 ; P=0,04)$. Também foi verificado melhor conforto com a cadeira específica para assento $(Z=2,04$; $P=0,04)$, encosto $(Z=2,04 ; P=0,04)$, apoio para os pés $(Z=2,04 ; P=0,04)$ e aro de propulsão $(Z=2,04 ; P=0,04)$. A Figura 4 apresenta os valores médios e o desvio padrão dos resultados da escala de conforto fornecida logo após a realização do teste de velocidade sem bola (Figura 4).

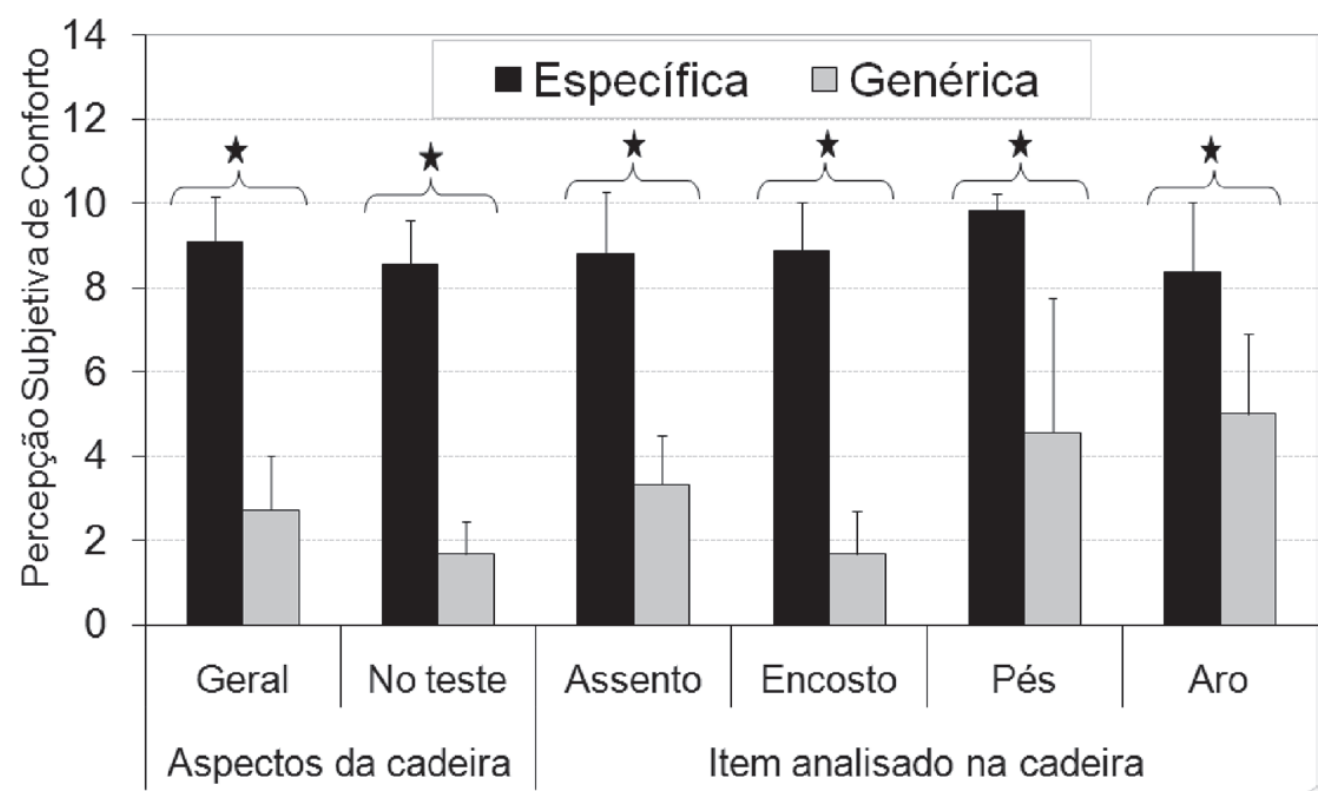

Figura 4: Escala de conforto (média e desvio padrão) no teste de velocidade sem bola realizado com a cadeira específica e genérica.

Nota: *diferença significante $(P \leq 0,05)$ entre a cadeira específica e genérica.

Os participantes apontaram maior conforto utilizando a cadeira específica para todos os itens analisados: assento $(Z=2,04 ; P=0,04)$, encosto $(Z=2,04 ; P=0,04)$, apoio para os pés $(Z=2,04 ; P=0,04)$ e para o aro de propulsão $(Z=2,04 ; P=0,04)$. Deste modo, nos itens cadeira em geral $(Z=2,04 ; P=0,04)$ e durante a realização do teste $(Z=2,04 ; P=0,04)$ também foi verificado maior conforto utilizando a cadeira específica. A Figura 5 apresenta os valores de média e de desvio padrão da escala de conforto, utilizando a cadeira específica e genérica, após o teste de velocidade com bola. 


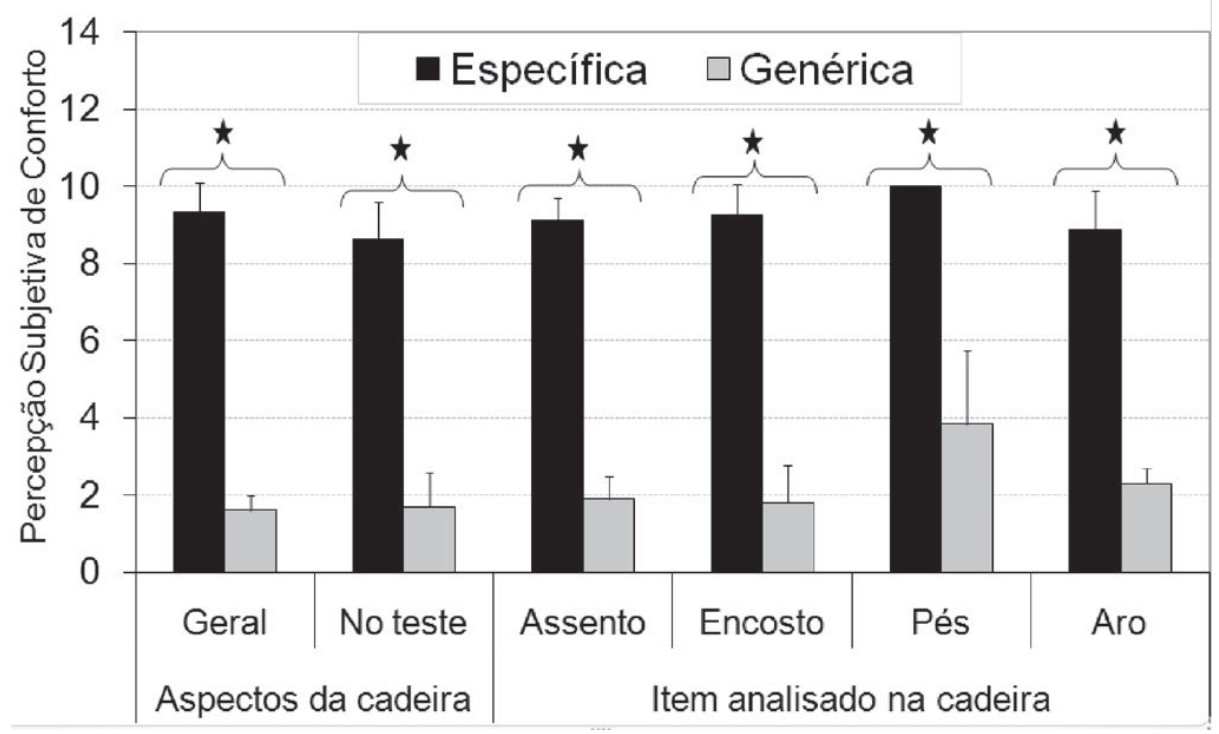

Figura 5: Escala de conforto (média e desvio padrão) no teste de velocidade com bola desempenhado com a cadeira específica e genérica.

Nota: *diferença significante $(P \leq 0,05)$ entre a cadeira específica e genérica.

No teste de agilidade em ziguezague, foi verificado melhor conforto com a utilização da cadeira específica nos itens de cadeira de uma maneira geral $(Z=2,04$; $P=0,04)$ e para a cadeira durante a realização do teste $(Z=2,04 ; P=0,04)$. A cadeira específica também demonstrou melhor conforto nos itens de assento $(Z=2,04$; $P=0,04)$, de encosto $(Z=2,04 ; P=0,04)$ e de apoio para os pés $(Z=2,04 ; P=0,04)$. Para $\circ$ aro de propulsão $(Z=1,78 ; P=0,07)$ não foram encontradas diferença significativa quando foram comparadas as duas cadeiras. A Figura 6 apresenta os resultados da escala de conforto (média e desvio padrão) após a realização do teste de agilidade em ziguezague com a cadeira específica e genérica.

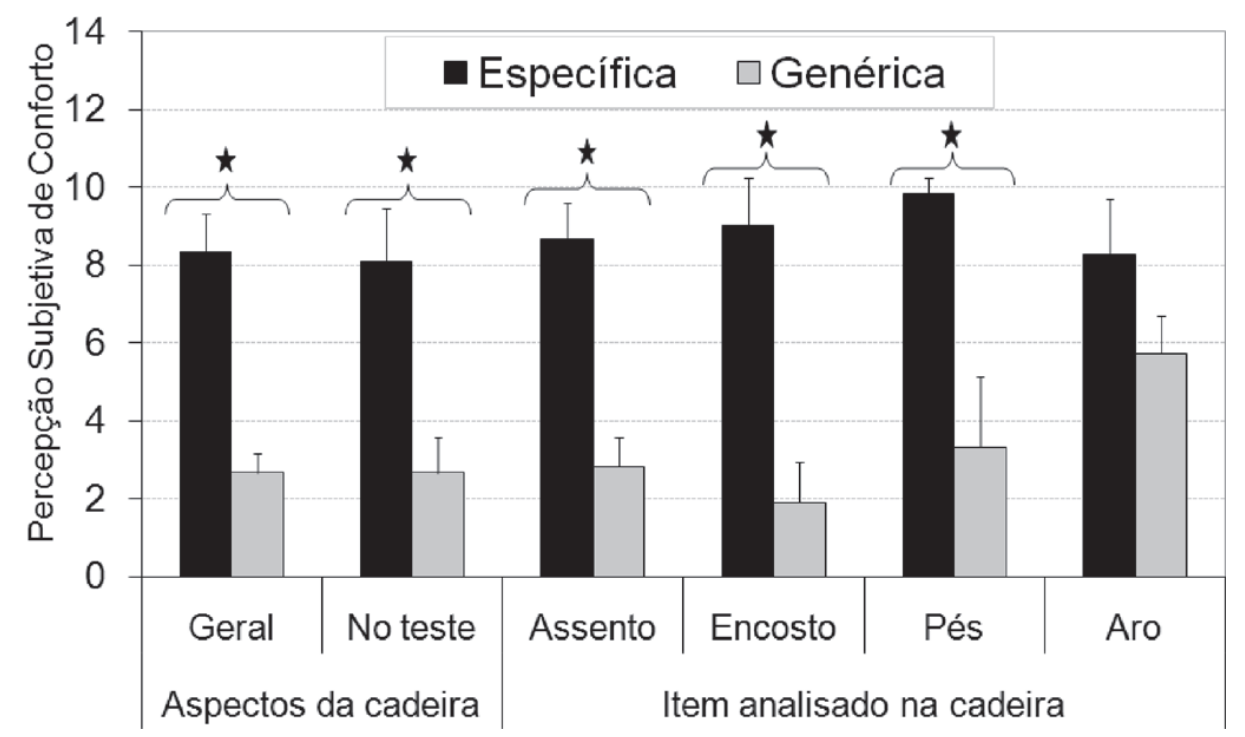

Figura 6: Escala de conforto (média e desvio padrão) no teste de agilidade em ziguezague sem bola desempenhado com a cadeira específica e genérica.

Nota: *diferença significante $(P \leq 0,05)$ entre a cadeira específica e genérica. 


\section{DISCUSSÃO}

O presente estudo analisou o efeito sobre o desempenho esportivo e o conforto proporcionado com a utilização de cadeiras de rodas prescritas (específicas) e não-prescritas (genéricas), em função da particularidade de cada participante de basquetebol em cadeira de rodas. Para tanto, foram realizados três testes (velocidade de 20 metros com e sem drible, e agilidade em ziguezague sem drible), nos quais foram analisados os desempenhos e o conforto com a utilização das cadeiras específicas e genéricas.

Foi verificado melhor desempenho para a cadeira específica em todos os testes realizados. Por conseguinte, a utilização de cadeiras específicas, em função das limitações e potencialidades dos atletas, auxilia na otimização de seu desempenho. Esta prescrição, entretanto, necessita do conhecimento específico das partes que compõem a cadeira de rodas e sua importância (MEDINA; COELHO, 2007). Geralmente, tem sido utilizado o mesmo procedimento de prescrição da cadeira de rodas convencional para a cadeira de basquetebol. Apenas são feitas adaptações mais específicas quando o participante apresenta alguma limitação que o impeça de ficar na posição comum na cadeira. Estas especificidades e cuidados demandam que a cadeira de rodas seja prescrita por um profissional habilitado e preparado para fazer as possíveis adaptações necessárias para a melhor acomodação do participante que irá utilizá-la (MEDINA; COELHO, 2007).

A vantagem no desempenho utilizando a cadeira de rodas específica foi explicada pelos indicadores da escala de conforto utilizada no presente estudos. A escala de conforto apresentou diferença em quase todas as variáveis analisadas. Tais resultados foram explicados pela ergonomia da cadeira adaptada especificamente para atender às características específicas de cada participante. Por exemplo, o assento da cadeira de rodas apresentou diferenças em todos os testes analisados, no qual houve maior conforto para a utilização da cadeira específica. Segundo Gettel e Redford (1995), é importante considerar as forças atuantes na postura sentada, pois a pressão exercida nessa região pode causar úlceras de pressão (escaras). Para o participante com lesão medular é indicado que o assento da cadeira seja flexível para diminuir essa pressão na região pélvica. Este desconforto relatado pelos participantes na realização dos testes com a cadeira genérica que possui assento rígido corrobora com os cuidados apontados por Gettel e Redford ( 1995). Todavia, como o período de realização dos testes ocorreu de forma rápida, não foi relatada lesão decorrente da cadeira genérica durante os testes, mesmo com o alto grau de desconforto verificado. 
Com relação à largura do assento, é preciso medir o tamanho do quadril do participante. Tem sido sugerido que o atleta utilize a cadeira como se fosse parte de seu corpo, para proporcionar maior equilíbrio e estabilidade na realização dos movimentos no jogo. Deste modo, deve haver um ajuste adequado na largura do assento que permita maior estabilidade durante a realização de movimentos. Outro fator importante é que o protetor lateral não seja rígido. Principalmente em jogadores com lesão medular, para não gerar muita pressão sobre a lateral do quadril. Para algumas mulheres, sugere-se que a medida da largura do assento seja feita com pelo menos $1 \mathrm{~cm}$ a mais, pois em períodos menstruais a mulher retém líquido podendo aumentar sua medida de quadril.

O tamanho da medida do encosto está intimamente ligado com a profundidade do assento em sua parte traseira. Esta medida deixa o quadril mais baixo, dependendo da deficiência do participante e, no caso de lesão medular, depende da altura da lesão. $\mathrm{Na}$ qual, abaixando o assento em sua parte posterior, automaticamente aumenta a altura do joelho em relação ao quadril. Os testes motores apresentaram diferenças entre os dois tipos de cadeira. $\bigcirc$ encosto traz confiança para a pessoa que está acostumada com assentos mais altos, ou no caso da cadeira de rodas, a profundidade maior do assento, o que pode ter gerado desconforto quando os testes foram realizados com a cadeira genérica. $\bigcirc$ apoio para os pés também está ligado à altura dos joelhos na cadeira de rodas. Pois, os pés dos participantes precisam estar apoiados e amarrados (por faixas com velcro, por exemplo) para não desestabilizar (atrapalhar) nos movimentos realizados. Utilizam-se faixas com velcro para fixar as pernas e o quadril junto à cadeira, pois no basquete em cadeira de rodas não é permitido que o atleta utilize-se ilegalmente da sua força de quadril (se houver) para tirar vantagens em alguns movimentos. (CONFEDERAÇÃO BRASILEIRA DE BASQUETEBOL EM CADEIRA DE RODAS, 2008)

O centro de gravidade do corpo humano se encontra na proximidade da segunda vértebra sacral. Mas, esse posicionamento se modifica de acordo com a constituição anatômica que o corpo adota. Medina e Coelho (2007) sugerem que a prescrição de cadeira de rodas social permita que o eixo da roda traseira seja alinhado com o ombro do sujeito que utilizará a cadeira e que a posição anatômica na postura assentada seja de $90^{\circ}$ no encosto e $90^{\circ}$ nos joelhos. Porém, na cadeira de rodas de basquetebol é mais difícil estabelecer os mesmos parâmetros de medição, pois o encosto da cadeira de rodas é mais baixo e muitos participantes não apresentam uma postura adequada. Ou seja, alguns participantes podem apenas em alguns casos apresentar o encosto com uma angulação de $90^{\circ}$. Todavia, os joelhos dependem muito da particularidade de cada participante, já que alguns atletas precisam que os 
joelhos fiquem mais elevados que o quadril para melhor equilíbrio e estabilidade durante seus movimentos. Nas cadeiras nacionais, de uma forma geral, ainda não é possível regular o centro de gravidade da cadeira de rodas. Alguns modelos de cadeira de rodas internacionais, entretanto, já disponibilizam essa possibilidade de regulação no centro de gravidade da cadeira de rodas.

Para o aro de propulsão só não foi encontrada diferença significativa para o teste de agilidade. Este resultado foi explicado pelo fato do teste de agilidade ter sido realizado de forma mais lenta e com mais cautela, devido às mudanças de direção no percurso. Por outro lado, no teste de velocidade, foi objetivada grande geração de velocidade, no qual alguns participantes apresentaram maior dificuldade em sincronizar os movimentos necessários de propulsão para tocar o aro da cadeira genérica. Por conseguinte, foi relatado menor conforto também no item de tocar a cadeira.

Outra explicação para o melhor desempenho nas cadeiras específicas foi o fato de que estas eram as cadeiras que cada participante utilizava em suas práticas e treinamentos no basquetebol. Ou seja, existiu um efeito crônico de adaptação em relação às cadeiras específicas e apenas um efeito agudo de adaptação para a utilização da cadeira genérica. Esta explicação está em consonância com o estudo realizado por Gorla, Araújo e Carminato (2005). Estes autores analisaram seis participantes (com Poliomielite) no teste de velocidade de 40 metros em cadeiras de rodas. Foi demonstrado melhor resultado para os participantes com maior tempo de prática (GORLA; ARAÚJO; CARMINATO, 2005). Gorgatti e Böhme (2003) também verificaram melhor desempenho no teste de agilidade em 10 participantes atletas, em comparação aos outros 10 participantes sedentários utilizados no estudo. Mesmo após um período de adaptação de duas horas fornecido aos participantes sedentários na cadeira de rodas esportiva, um dia antes do teste, esse tempo não foi suficiente para fornecer uma adaptação dos participantes à cadeira.

\section{CONCLUSÃO}

A utilização de cadeira de rodas específica para cada participante apresentou melhor desempenho na realização dos três testes. Por conseguinte, foi sugerido que a cadeira de rodas feita sob medida para cada participante é o mais indicado, já que esta está intimamente ligada ao desempenho esportivo do participante e ao melhor conforto fornecido pela cadeira. Deste modo, também auxiliando na prevenção de lesões tal como escaras e a piora na postura corporal. Foi levantada a hipótese de que os participantes apresentariam melhores desempenhos nos testes de velocidade de 20 metros sem bola, no teste de velocidade com bola e no teste de agilidade de ziguezague com as cadeiras feitas sob medida, e também que participantes apresentariam melhores resultados na escala de conforto com a utilização cadeiras feita sob medida. Os resultados apresentados no presente trabalho sustentaram as hipóteses inicialmente formuladas. 
Recomenda-se que mais estudos sejam realizados dentro da temática de prescrição de cadeiras de rodas. Sugere-se também a análise de diferentes particularidades no que diz respeito aos graus de lesão e comprometimento motor.

\section{The effect of basketball wheelchair prescription over the performance of the modality players}

ABSTRACT: It was analyzed the athletic performance in basketball players using wheelchairs prescribed (specific) and not prescribed (non-specific) according to the particularity of each player. Six wheelchair basketball players performed the 20 meters speed test (with and without dribbling a ball), and the agility test without dribbling a ball. Scales of effort and comfort were used after each test. It was verified better performance $(P<0,05)$ and comfort $(P<0,05)$ in the tests performed with the use of the prescribed wheelchair. Therefore, it was suggested that the use of prescribed wheelchair specially designed for each athlete, for the optimization of their performance and comfort in the basketball wheelchair sport.

KEYWORDS: Prescription of wheelchairs; basketball wheelchair; sports performance; ergonomics.

\section{El efecto de la prescripción de silla de ruedas del baloncesto en el rendimiento deportivo}

RESUMEN: Se analizó el desempeño deportivo de jugadores de baloncesto con la utilización de sillas de ruedas prescriptas (específicas) y no prescriptas (generales) de acuerdo a las características de cada atleta. Seis participantes desarrollaron pruebas de velocidad $(20 \mathrm{~m}$ con y sin balón) y de agilidad (sin balón). Escalas de apreciación de esfuerzo y de comodidad fueron utilizadas después de las pruebas. Se verificaron mejores desempeños y comodidades en las pruebas realizadas con la utilización de sillas prescriptas. Se sugirió el uso de sillas prescriptas específicamente para cada atleta, a fin de optimizar el desempeño y la comodidad para la práctica de baloncesto en silla de ruedas.

PALABRAS CLAVE: Prescripción de sillas de ruedas; baloncesto en silla de ruedas; rendimiento deportivo; ergonomía.

\section{REFERÊNCIAS}

ADAMS, R. C. et al. Jogos, esportes e exercícios para o deficiente físico. 3. ed. São Paulo: Manole, 1985.

BORG, G. Escalas de Borg para a dor e o esforço percebido. São Paulo: Manole, 2000.

CALEFFI, G. D. Treinadores de basquetebol em cadeiras de rodas: seus conhecimentos, concepções e prática. Estudo de caso de dois treinadores do escalão sênior da região norte de Portugal. 2008. 204 f. Dissertação (Mestrado em Ciências do Desporto)-Faculdade de Desporto, Universidade do Porto, Porto, 2008. 
CONFEDERAÇÃO BRASILEIRA DE BASQUETEBOL EM CADEIRADE RODAS. Regras oficiais de basquetebol em cadeiras de rodas 2008. 86p. Disponível em: < http://www.jnrwebsite.com. br/cbbc/images/stories/download/Regras_2008.pdf>. Acesso em: 7 maio 2010

FREITAS, P. S.; CIDADE, R. E. Paraolimpíadas: revisando a história. SOBAMA, São Paulo, v. 7, n. I, p. $21-26$, dez. 2002.

GETTEL, A. H.; REDFORD, J. B. Wheelchairs and wheeled mobility. In: REDFORD, J. B.; BASMAIIAM, J. V.; TRAUTMAN, P. (Ed.). Orthotics: clinical practice and rehabilitation technology. New York: Churchill Livingstone, 1995. p. 17।-217.

GORGATTI, M. G.; BÖHME, M. T. S. Autenticidade científica de um teste de agilidade para indivíduos em cadeira de rodas. Revista Paulista de Educação Física, São Paulo, v. I, n. I7, p. 4I-50, jan./jun. 2003.

GORGATTI, M. G.; GORGATTI, T. O esporte para pessoas com deficiência. In: GORGATTI, M. G.; COSTA, R. F. Atividade física adaptada: qualidade de vida para pessoas com necessidades especiais. 2. ed. Barueri: Manole, 2008. p. 532-570.

GORLA, J. I.; ARAUJO, P. F.; CARMINATO, R. A. Análise das variáveis motoras em atletas de basquetebol em cadeira de rodas. Lecturas Educación Física y Deportes, Buenos Aires, v. I0, n. 83, abr. 2005.

GORLA, J. I.; CAMPANA, M. B.; OLIVEIRA, L. Z. Teste e avaliação em esporte adaptado. São Paulo: Phorte, 2009.

INTERNATIONAL WHEELCHAIR BASKETBALL FEDERATION. Disponível em: < http:// www.iwbf.org/>. Acesso em: 7 maio 2010.

MEDINA, A. G.; COELHO, D. B. Aspectos biomecânicos e funcionais na prescrição de cadeira de rodas. In: CONGRESSO BRASILEIRO DE BIOMECANICA, I2., 2007, São Pedro. Anais... São Paulo: TEC ART, 2007.

WINNICK, J. P. Educação Física e esportes adaptados. E. ed. Barueri: Manole, 2004.

Recebido: 16 fev. 2011 Aprovado: 26 maio 2011

Endereço para correspondência Victor Hugo Alves Okazaki Universidade Estadual de Londrina - Departamento de Educação Física Campus Universitário - Rodovia Celso Garcia Cid Km 380 Londrina - Paraná - Brasil Caixa Postal: 600I - CEP: 8605I-990 Site: http://okazaki.webs.com 